Post-print version. Full reference: Nielsen, H.B. (2019). "Bodies and boundaries in three generations." Eds. S.Pickard and J.Robinson. Ageing, the Body and the Gender Regime. Health, Illness and Disease across the Life Course. London: Routlegde.

\title{
Bodies and boundaries in three generations
}

\section{Harriet Bjerrum Nielsen, Centre for Gender Research, University of Oslo}

January 292019

\section{Abstract}

Young people today, and in particular young women, report increasing level of stress, eating disorders, feeling of depression and dissatisfaction with their bodies. This scenario comes from a generation and class of young women who have never had so many chances in life - both in regard to education, careers and personal life - and who are doing very well. This chapter discusses this paradox in a generational perspective, conceiving the body in a broader context of age, relationships, development and agency. By analysing how young women and men's feelings about their bodies have changed over three generations, the chapter explores the relation between subjectivity, bodily pleasure and concern and how this may reflect and express the changing social conditions for the development of gender identity, autonomy and intimacy. In the concluding section I will discuss what further transformations of bodily and psychosocial shifts we might see in young people today - representing the "fourth generation" in relation to my study.

Bodies are significant issues for most young people and a central site for the production of subjectivities and gender. This appears to be true across cultures and generations, albeit in different ways and with different emphasis (Smolak, 2004; Holmquist and Frisén, 2010; Ricciardelli and Yager, 2016; Nielsen 2017). Social studies of body images have, since this area of research emerged in the mid 1980s, documented a marked rise in dissatisfaction with looks and appearances among young people (Holmquist Gattario et al. 2014; Sletten and Bakken 2016). An overall estimate in the research literature is that around $30-40 \%$ of young people in the West 
today are dissatisfied with their bodies or some parts of them (Smolak 2004; Currie, 2012, Frisén et al., 2014). Even though the numbers are rising also for boys, dissatisfaction is much more common among girls. ${ }^{1}$ Their concerns about the body start earlier than the boys' and the dissatisfaction continues into early adulthood. They are more prone to self-objectification, often leading to increased self-surveillance, body shame, and belief in appearance control (Holmquist Gattario et al., 2014; Ricciardelli and Yager, 2016). For girls, it is mainly the aesthetic qualities of the body that is in focus: they want to be thinner and believe that this would make them happier and more successful with boys (Smolak, 2004; Kvalem, 2007; Wertheim and Paxton, 2012). In a Swedish longitudinal study following 1000 children from when they were 10 years old, more than half of the girls were on a diet at the age of 16 , whereas the same was "only" the case for 16\% of the boys (Frisén et al., 2014: 98). For the boys the focus is typically on lean muscularity and they tend to have their focus more on the functional than the aesthetic aspects of the body, for instance, a body that is good in sports. Even though it also requires an effort to keep up muscularity, the male body ideal is more attuned to the physiological development in adolescent boys than the female ideal of thinness is to the physiological development in adolescent girls (Kvalem 2007; Holmquist Gattario et al., 2014). Most of the studies stem from Western countries, however, also studies from non-Western countries indicate widespread body image concerns in adolescence today (Wertheim and Paxton, 2012; Holmquist Gattario et al. 2014; Ricciardelli and Yager, 2016) as well as similar gender differences. Modern Western ideals about thinness for girls and V-body shape for boys have become a transnational phenomena through processes of globalisation and mediatisation (Tiggemann 2012). Furthermore, ideas about what a "normal" body and appearances are have become far more hegemonic and homogenised within the last decades and are increasingly based on 'illusory women (devised from carefully constructed photo images and film angles) against whom [the young women] may all feel more or less inadequate (...) any imperfection may be seen as "unnatural"' (Frost, 2005: 80, see also Wertheim and Paxton, 2012).

Even though worries, dissatisfaction, shame and anxiety with one's body is not a new or solely Western phenomena, the dramatic increase of this, especially for girls and young woman and especially in affluent countries with a Western life style (high consuming and individualistic) are indisputable (Holmquist and Frisén, 2010). Today, the most important factor for young people's self-image is the body, and 
especially for the girls (Holmquist Gattario et al., 2014; Madsen, 2018).

Dissatisfaction with the body is associated with negative wellbeing like depression, eating disorders, low self-esteem, and health-compromising behaviours (Wichstrøm, 1999; Wertheim and Paxton, 2012; Holmquist Gattario et al., 2014). Young people in affluent countries today, and in particular young women, report increasing level of stress, eating disorders, and feeling of depression (Holmquist Gattario et al., 2014; Sletten and Bakken 2016). ${ }^{2}$ Paradoxically, this scenario comes from a generation of young women who have never had so many chances in life - both in regard to education, careers, economy and personal life - and who on a broad scale are doing very well. ${ }^{3}$ Low self-esteem and psychological stress have the highest prevalence among those who do not do well in school, but there has been a marked increase also among those who do well, in particular middle-class girls (Kvalem and Strandbu, 2013; Sletten and Bakken, 2016; Eriksen et al., 2017; Bakken, 2018). The relatively gender-equal Nordic countries make no exception here, rather the opposite.

\section{Bodies in time and place}

Historical studies indicate that body and appearances became more central for selfidentity and self-esteem from the 1920s onwards with the emergence of new mass media representing a new kind of cultural mirror. Appearances gained importance especially for young girls in this generation, when compared to the Victorian ideal of inner beauty and the rural and working class values of the working body (Brumberg, 1997; Søland 2001). The body became a project and image became identity, as Joan Jacobs Brumberg coined it (1997:104), the ultimate expression of the self, as other sources of social identity connected to family, community, class and religion were gradually weakened in the modern society. Sociological theories of the late-modern reflexive subject emphasising the dimension of self-construction, self-obsession, selfcontrol and self-responsibility, also foregrounds bodily appearance as having a special significance: 'The tightly controlled body is an emblem of a safe existence in an open social environment' (Giddens, 1991:107). In feminist research, women's occupation with body and appearances has been seen as product of the Western split between body and mind, modern individualism, late consumer capitalism, an increasingly sexualised media culture and new body technologies (Bordo, 1993, Davis, 1995; Frost, 2005; Gill, 2007; Kehily, 2008; McRobbie, 2009). 
The interaction between the body project, modern consumer culture and the rising demands of perfection and competitiveness in the neo-liberal context has been seen as particulary toxic for young people and associated also to the paradox between young women's increasing educational success and increasing symptoms of bodily dissatisfaction and psychological stress. It has also been seen as a new context for feminism where the equation of freedom with the free choice in the market simultaneously feed on and undermine the feminist struggle for women's right of selfdetermination. Feminist discontent appears to have been replaced 'by an aggressive individualism, by a hedonistic female phallicism in the field of sexuality, and by obsession with consumer culture' (McRobbie, 2009:5, see also Kehily, 2008). McRobbie argues that this neo-liberal shaping of female subjectivities represents 'a new sexual contract', which on the one hand gives young women access to education and career in a hitherto unseen extent, and on the other hand reinforces gender difference and heteronormativity through a retraditionalisation - as a matter of choice, not obligation - of fashion and beauty standards which underlines women's fragility, harmlessness and subordination. This image of the feminine re-instates symbolically masculine power and heterosexual desire in a situation where women have become less economically and personally dependent on men (McRobbie, 2009: 62). Harris (2004) and Aapola et al. (2005) have argued that this has lead to a split in the cultural image of young women as autonomous and strong 'can-do' girls versus vulnerable 'at-risk' girls, something that may also be connected to the cultural ambivalence towards the young girl as both 'the promise and the failure of the modern' (Driscoll, 2002:303).

The analyses of the post-feminist and neo-liberal condition have their focus on the cultural representations and the discursive shifts about young women. As valuable as they may be as diagnoses of contemporary culture and society, they contribute little to the understanding of how gendered subjectivities come into being, why young women (and men) adapt to these representations, what meaning they may have for them and what practices they become part of. As Liz Frost (2005) has argued, there is a tendency both in media and in research to reduce girls to their bodies, rather than looking for the girl in the body. Young people may have other issues and desires than adults, and age, subcultures and group belongings are important dimensions to take into account when processes of regendering are considered (Skeggs 1997; Frost, 2005; Kvalem 2013). Questions like these have been given attention within feminist 
youth studies, focussing more on young people's agencies (for instance, Lees, 1993; Skeggs, 1997; Holland et al, 1998; Bengs, 2000; Oinas, 2001; Frost, 2001;

Ambjörnsson, 2004). What many of these studies share with the cultural investigations of the neo-liberal gender representations, however, is a short time perspective where social change at its height reaches back to the 1970s and 1980s, a period of time when youth studies, gender studies and the social studies of body images themselves first emerged. By this temporal framing, the present body concerns among young women risk being understood primarily as a product of emerging neoliberalist arrangements that are directly converted into new self-regulating feminine subjects. Inherent in this is also a construction of discontinuity between feminist discontent and agency of the 1970s and docile young feminine bodies of the new millennium.

In this chapter I want to investigate young people's lived relation to their bodies in a longer time perspective and see to what extent this may shed light on the present paradox in many young women's lives. I understand the body issue in a broader context of age, relationships, development and agency. I will show that the changes in gendered subjectivities and concerns about the body over these three generations have been incremental and ambiguous, containing both pleasures and pain, aspects of liberation and agency as well as new kinds of inhibition and control. It is seldom possible to judge the liberating or inhibiting potential from the face-value of young people's behaviour; what looks incredibly conformist seen in a synchronic view may sometimes be steps in a longer process of change when seen diachronically and as part of a generational transition (see also Kehily, 2004). In the following analysis I will therefore look into the relation between subjectivity, bodily pleasure and concern in young women and men's lives in three generations and see how this may reflect and express different conditions for the development of gender identity, autonomy and intimacy. The meanings of the reproductive, the aesthetic and the sexual body will be understood not only in relation to the shifting cultural ideals of masculinity and femininity, but also to the psychological work they represent in the processes of growing up. In the concluding section I will return to the paradox in young women's lives and look at cross points between the generational story and the present situation. I will also shortly discuss to what degree the increased body concerns, reportings of stress and eating disorders may be seen, at least partly, as 
reinforced by new available discourses coming not only from the media, but also from research itself.

\section{A three-generational study}

The empirical example is taken from a three-generational study of young Norwegian women and men born in 1971/1972, their mothers/fathers born around the Second World War (the 1940s and 1950s) and their grandmothers and grandfathers born around the First World War (most of them in the 1910s and 1920s). The aim of the study was to understand more of how cultural modernisation has been intertwined with the psychological project of becoming an adult in these three generations. ${ }^{4}$ The three generations were interviewed about their childhood and youth in 1991, when the youngest generation were in their last year of high school. The youngest generation were reinterviewed in 2001 and a few of them again in 2011. Thus, the study makes use of biographical, generational, and longitudinal methods. Before the initial interviews in 1991 we did classroom observations in five classes in two high schools in Oslo, Norway, with different social profiles. Approximately half of the students were invited to a life-historical interview and after this we interviewed the girls' mothers and maternal grandmothers and the boys' fathers and paternal grandfathers, using the same methodology and approximately the same semi-structured questionnaire as with the youngest generation. ${ }^{5}$

In the analysis in this chapter I will focus on some of the changing generational patterns in young women and men's relation to their bodies and appearances. All the interviewees within a generation do not, of course, fit equally well in these patterns, however, the individual and cultural variation will not be examined here except for some indications of the significance of class. Since we chose the academic lines in the two city high schools, the sample turned out to be characterized by a high degree of social mobility over the three generations. Whereas a vast majority of our youngest generation took higher education, many of them had parents who belonged to the lower-middle class or working class, mostly urban. A majority of the grandparents grew up in the countryside as sons and daughters of farmers, fishers, and smallholders. This is not an atypical generational trajectory for these three generations, as Norway came later to industrialization and urbanization than many other European countries. In this perspective, the sample is rather typical for the huge processes of urbanization, rising education and welfare that took place 
during the twentieth century in Norway, but it still has a bias towards those who actually ended up in the urban middle class at some point.

It is important to keep in mind that all three generations were interviewed at the same point in time, which means that their narrative constructions are from 1991 (or, in the case of the second and third interview of the youngest generation, 2001 and 2011). Thus, later experiences and discourses work as selective filters in their recollections of childhood and youth. However, the generational patterns indicate that there are indeed experiences to be interpreted, not only inventions from the present. Another consequence of interviewing all three generations at the same point in time is that they talk from different life phases and, thus, have different temporal distance to their childhood and youth. This is seen in the ways they talk, what they emphasize in their recollections, and their evaluations of their experiences. To some extent, the different discourses used by different generations may also be seen as 'small pockets of history' that have been preserved in the individuals through changing times. In our analytical work we endeavoured to take these differences into account in the interpretative work by keeping three analytically related questions in mind: What is the historical experience conveyed in the interview? How does the narrative style and later discursive filters form the memory? And, finally, how do we ourselves as generationally and class-positioned researchers contribute to the creation of meaning in what the interviewees tell us, as interviewers as well as analysts? ${ }^{6}$

\section{(Female) bodies and (male) sexuality}

For both women and men in the eldest generation, bodies and especially the generative and problematic aspects of bodies, are more or less associated with women, whereas sexuality is construed as an exclusively male urge to be lived out or kept in check. The men often inform us about injuries and diseases, both due to the war and their old age. However, these stories are still associated with male strength and outward activity, since they are usually told in order to underline the importance of enduring and overcoming personal bodily suffering. John, born 1919, working class, says this when he is asked about how he perceived his body as a young man:

I was called a weakling when I was young, but I have developed since then. I started work in a workshop when I was 17 and the tools were very heavy. I tried to work out in gymnastics, like you know today they do weightlifting. Until then I had only been to school, so I was quite weak. But after the first year at work I wasn't weak 
anymore. I remember working with the sledgehammer, that was really hard. But I've always been like that, when I work I make an effort, giving the best I can.

The experiences of their own bodies reflect their general mentality of work, their strong and mainly positive identification with their fathers and their feelings about masculinity. Gender complementarity in this generation is so self-evident that it becomes invisible for them. They tell about their tender feelings for their hardworking mother, however, she belongs to a different order than themselves and her mildness and weakness is perceived as part of her femininity. The contempt for male weaklings who lack the stamina to overcome troubles in life is often brutally clear, and the taboo against complaining is evident. It is not unreasonable to interpret this as a defence against the fear of losing masculinity. One of the men says in the interview that, in his eyes, a man who is occupied with his appearance is not a man. The self-evident masculinity personified in the strong, working body is also important as part of a competitive comparison between men, often in connection with size and strength. At the same time as size/strength are important factors, they should come 'naturally' (meaning through work) and the body itself is not yet objectified or dwelt upon unless it fails as an instrument. The interest in bodies per se is felt as feminine, and biological, age-related changes ('puberty' is not yet a term common in this generation) are associated with girls, not boys.

In many ways the women confirm the men's conception of the body as a particularly female sphere of interest. Although some working-class and farmer girls deny having had any time to 'sit and mope' over their own bodies, there is no taboo on talking about the sick or suffering body. In fact it seems that it is only when the generative body can be understood as a sick body (and not as a sexual body) that it can be talked about at all. It is not hard to get the women to talk about their menstruations. Mundane activities like knitting and washing sanitary towels, then hanging them out to dry in public, make the generative body a constant presence in their lives. For most of the women menstruation forms a narrative of being scared almost to death as a totally unknowing young girl, then silence about what had happened and excruciating pain. Some of the women talk about the relief they felt when they finally reached menopause. The discourse is quite straightforward: this is the 'women's curse,' literally revealing the shame associated with one's own bodily impurity. The body gains more positive connotations when it comes to appearance. A 
nice figure and thick or curly hair was a good resource on the marriage market, in addition to being good at household work. Johanna, born 1910 as the daughter of a small farmer recalls going to the village dances as an adolescent girl:

Yes, it was exciting! We finished our work in the stable in the evening, and if one had a new dress to wear it was something special, then shoes and stockings, and...I've never had any problems with my hair for it was a bit curly by nature. (...) I was very happy with my figure because I had no problems regarding that, and I started to understand what that meant. Whereas the others had to struggle with curling irons it was just combing your hair and then you were ready.

If you did not possess any of these bodily advantages, there was not much to be done about it. Nobody remembers dieting, but as Johanna says, many of them put effort into getting their hair done. Only among the middle-class girls do we hear about more specific worries like an ugly nose, short legs or pimples, but there was not much they could do about those either.

Seen in a psychosocial perspective, the self-evident male body in this generation seems to be part of the strong same-sex identification among the men, emotionally invested in the ideal image of the father - but also involving an undercurrent of possible humiliation and competitive loss both in comparison with other men and with regard to the fear of female weakness. For the women there is an inherent ambivalence in the same-sex identification with the mother, who is both competent and yet not quite what one wants to emulate. This might be reflected in the way they relate to their own generative body as more of a burden than a source of pleasure. It is the fathers, often remembered as generous, playful and knowledgeable figures who are the admired parent for the daughters, but who, alas, belong to a masculine world that is inaccessible to them as girls.

If the body is understood as 'female' immanence by both men and women in this generation, sexuality is as clearly and unanimously understood as 'male.' However, some of the gender similarities in practice are surprising: the norm of abstaining from sex at least until formally engaged was quite strong for both the women and the men. Some of the men are quite vague about sexual activities, but indicate both feelings of guilt, considerations for the girl and the necessity of selfdiscipline. At the other extreme, a working-class man tells us about his wild youth, involving a lot of female liaisons and detailed prescriptions for seduction. But even such sexual excesses are socially regulated: starting a family acts as a sharp boundary between wild, irresponsible youth and grown-up masculinity. Although male 
sexuality has to be kept in check, even harsher rules apply to women: while men can be wild for a certain period and then develop into responsible adults, women do not enjoy the same freedoms. To the men the possibility of active female sexuality seems to go against nature, and the few who have experienced being approached by women find it almost monstrous. They cannot relate female sexuality to their emotional experiences of femininity, and sometimes their unconscious fears about it are activated. The women themselves also stick to the distinction between 'cheap' and 'nice' girls and according to all the women in the eldest generation, the positive aspect of the strict norms was the lack of pressure on a girl to have sex before she was engaged. If a girl was pressured, she was in her unquestionable right to say no. Unlike the men, none of the women say that following those rules was in conflict with their own sexual needs. The women are even less willing than the men to talk about their own sexual experiences in the interviews. To be disinterested in sex appears as a fact of life, a part of female nature, maybe even inherited from their mother.

Although sex is depicted as something one engaged in primarily for the husband's sake, there are also stories of youthful attractions to rather 'wild' and dangerous young men, good-looking and good at dancing. However, regardless of class, there were strict limits to observe. The female informants have little empathy with girls who became pregnant out of wedlock, thereby imposing great social shame on their parents. For many of the women, especially those who grew up in rural areas, deliberations when it came to marriage followed a different logic than their youthful infatuations: the exciting dancers were rejected in favour of men who had the potential of becoming solid providers in marriages based on complementary gender roles. It is not difficult to understand that accepting a decent marriage proposal in this generation could be a result of pragmatic considerations. But by silencing their own youthful attraction to the wild and dangerous men, they also split the relationship with the husband off from the image of the playful, fascinating father. The men, on the other hand, could in many ways safeguard the image of the 'good' mother in the shape of their wives, including their feelings of guilt towards this kind angel.

\section{Sexualising the body}

The parental identifications in the middle generation are very different from the ones in the previous generation. There is a marked crossover pattern where both daughters and sons tend to disidentify with their same-sex parent and feel most at ease with the 
other-sex parent. The girls report emotional difficult relationships with their stayhome mother and they identify with the more independent life of their father. The boys feel at distance from their absent, working fathers and value the emotional care and presence of their mothers, however, they do not take her as a model for their own life when it comes to education and work as the girls do with their father. In this psychological constellation it appears that the same-sex peers gain importance as gender models. In addition to his absence, the boys also saw their fathers as too 'oldfashioned' to emulate in these new, dynamic times. For the women, both female friends and heterosexual relations appear to have become important sources of closeness as well as liberation from their mothers in a situation where they still lacked sufficient psychological autonomy to be on their own. These gendered peer relations and the new flourishing youth cultures they were part of were to a high degree mediated through bodily practices.

The men in this generation perceived, as their fathers did, their bodies as unproblematic: 'No, I can't remember that being a problem. It has been fine' is the immediate response from a man in this generation when asked about how he experienced his body when he came of age. The self-evident body is no longer connected with the mentality of work but rather with sports and physical competitions, which seem to have replaced work as the arena for masculine bodily achievements. John's son Jan, born 1947, also working class says this:

Well... I have always liked my body, I have liked ...well, I'm not sure what you mean? (The interviewer explains). Just normal. (Interviewer explains again) I mean, I'm nothing special. That is, I haven't had any negative attitude to my body. I am $1.80 \mathrm{~m}$ and that's normal. I've done quite well in sports and other things. (Interviewer asks about body changes in adolescence). Well, I started quite early, I guess around $11-12$ years. I thought there was something wrong with me. (Interviewer: the first ejaculation?) Yes, yes. We had talked a bit about it at school, our teacher was quite open about it, so... but still it came as quite a shock (laughs).

The insistence on body strength coming 'naturally' is the same as in the previous generation, implying, for instance, that bodybuilding is scorned as effeminate 'selfindulgence.' In one respect the body has become a more explicitly male issue in this generation, evident in the worry about what their bodies reveal about their masculine sexual identity, and especially whether their genitals were masculine enough. When a man in the oldest generation was asked about puberty, he started talking about the war instead. When his son is asked the same question, he relates in detail to his own 
bodily insecurity, especially the size of his penis. Thus, we are able to discern a new vulnerability and self-objectification in men in this generation, but it is also an objectification that puts more emphasis on sexuality. This sexualisation of the body is even more evident when they talk about the female body and the importance they give to the physical attractiveness in women.

Also for the women in the middle generation, the body is much more in focus than for the women in the eldest generation, but also more problematic than for the men in their own generation. The relation to the generative body is now the least of the problem. Half of the women were informed by their mothers in advance, the rest knew about it from their friends. Puberty is discursively installed as a life phase and questions about 'when did you feel that you were grown-up?' are most often answered with ' $m y$ first period,' in contrast with the eldest generation who mentioned their confirmation and end of school when asked the same question. In this generation it is also less problematic to tell the mother about what had happened and get her to help with sanitary belts and pads. The experience of menstruation is more varied than it was among their mothers, who all felt that it was a 'curse.' The women in the middle generation are more ambivalent - menstruation is a nuisance but also a fact of life.

The sexualisation and gendering of the body become most evident in the women's intense beauty routines. Compared with their mothers' innocent joy of getting new dresses and shoes, the practices of the women in this generation are much more elaborate and detailed. There is quite a lot of pleasure in this kind of beauty work, often done together with female friends. Fashion, consumption and a more sexualised youth culture are all involved in this process - and both the lack of samesex generational bonds and the heightened levels of conflict between daughters and mothers may promote the insistent wish to be different and to preside over their own bodies and looks. In the overwhelming number of cases, however, the project is described as a hopeless affair. Almost all the women remember having very negative feelings about their own bodies as young girls, and their stories circle around the new concept of 'flaws,' a word only used by the women in our interviews in this generation. Johanna's daughter Jorun, born 1943 in a farmer family as her mother was, recalls:

I really liked to dance, but I was very shy. (...) I always had the feeling of being so fat. A huge behind, and I wanted so much to wear jeans, but I was so fat, fat thighs 
and so. And I can't really have been like that - I've saved some of my dresses and my own daughters can't fit into them! I wished I had curls, of course, blonde hair, and slender, of course. I had teeth regulation and that was absolutely awful.

The contrast to the men is striking: the image of the relatively unproblematic bodies where only penis size and embarrassment when purchasing condoms were issues to worry about, is countered by the women's long list of flaws. 'I got nowhere with my looks,' a middle-class girl says, even if her mother told her that she was pretty. This is also the first generation that mentions dieting and exercising to keep their weight down. Some of the women remember weight loss that would have been understood as eating disorders today, but at that time their parents just wondered if they might have some caught some infection that caused them to lose weight.

Youth in this generation coincided with the period of the 'sexual revolution,' which obviously had an impact with regard to both discourse and behaviour, but again, in quite gender-specific ways. No one in this generation waits to have sex until they are engaged or married, but for the women their first time is most often with the partner they later marry, whereas for the men it is not. The fear of pregnancy is present for both genders, not due to social shame, as it was for the women in the previous generation, but to threatened freedom. Pregnancy meant that one 'had to marry,' and quite a few of both the men and the women in our sample experienced exactly this.

The looser norms seem to have left this generation in a void concerning what one should and should not do. The sharp line between nice and cheap girls that guided the informants in the eldest generation has become blurred. A new division between 'fun' girls and 'dull' girls arises. The 'fun' girls are the popular ones, the ones attractive to boys and the ones who are always invited to parties. The absence of moral standards seems to have promoted more individual reflections on personal morality, which again led to more variation in behaviour. A working-class girl recalls: 'I pondered a lot: what can one do? What can't one do? What do the others do? What can I do?' Some girls became extremely careful; others took advantage of the liberal norms and went around searching for exciting boys. But that the sexual pressure on girls became much stronger than in the previous generation is beyond doubt. Many of the working-class girls whose sexual respectability was more vulnerable than that of the middle-class girls solved the problem by entering into steady relationships at an early age. 
Also among the men in this generation we sense some confusion about what rules the girls followed and how to interpret the signals from them. Quite a few of the men experienced as young boys falling in love with a girl and being rejected for reasons they did not understand. Confused or not, what clearly has changed in this generation of men is that the feelings of guilt or shame that were so obvious among the eldest generation of men have disappeared, and the fear of hurting the girl also seems to have diminished. Some of the men seem to have grabbed whatever was offered them, but afterwards they describe these sexually active women as almost nymphomaniac, and not girlfriend material. Sexuality is clearly anchored in the body; almost what the male body is all about - and yet also seen as a separate thing, not really a part of the man himself. A man comments on his own youthful sexuality in this way: 'sex is something the body came up with.' .

Whereas the men occupy the new youth cultural arena with gusto, sexuality is not discussed in terms of female desire and satisfaction at all. Just like the men, the women reject the possibility of female initiative when they were young girls. Some of the women use the euphemism of being 'swept off their feet' to describe their infatuations, but we are a far cry from the more or less uncontrollable lust that the men in this generation describe. On the contrary, the heterosexual debut of the women is often depicted as rather indifferent or even hurtful. The most important and almost only legitimate reason for sex among the young women is to be in love, and romance is a much more elaborated theme among the women in this generation than in the previous one, where only some of the middle-class women talked about it. Yet this focus on romantic love often had a somewhat instrumental touch to it: across social class the young women's relationships with boyfriends often became part of the liberation from parents. That this relatively unprotected journey out into the world is quite risky is not so surprising given the stories we heard from the men. In some of our interviewees' cases the risks involved rape and abortions, with all the humiliation, anxiety and bodily pains involved. The paradoxical liberation through sexuality on the men's terms seems to have implied stronger gender differentiation and heterosexual normativity among young women in this generation, in spite of their identification with their fathers and dis-identification with their mothers. Yet, the lack of clear-cut moral guidelines also resulted in a stronger awareness of their own responsibility and a potential reflexivity with regard to the double standards involved. This may gradually have strengthened their psychological autonomy and instigated the 
frustration that for this generation of women did not remain a subdued irritation in the way it did for their mothers. However, this did not happen when they were young girls, but first as young adults, and often in connection with entering higher education.

\section{Gendering bodies and degendering sexuality}

Both women and men in the youngest generation talk a lot and in great detail about their bodies and this interest in the body is no longer an exclusively female affair. Just like their grandfathers and fathers before them, the men in the youngest generation report that their bodily changes were gradual and that the puberty of girls is probably a much more dramatic affair, but they do actually have narratives of wet dreams, growing hair in the groin and armpits, and change of voice pitch. 'Puberty' is now a commonly used concept and regarded as a relevant topic also among the men and 'flaws' is a term that this generation of young men makes use of without any hesitation. Being small, too fat, or having a small penis are frequent complaints - in addition to red hair and freckles, acne, a big nose, and a tendency to blush. One bodily theme that is recognisable across the generations of men, however, is the matter of size. This obviously includes the size of the penis, where comparisons in the school shower are still mentioned as shameful experiences. But the issue of size is more general: to be 'tall for one's age' or 'one of the tallest in class' is referred to as an important asset, almost negating other flaws. John's grandson Joar, born 1972, lower middle class, says:

I was very little, one of the really small ones, and I probably still am, but it's not so bad now as it was then, I was very little and was even sent to the GP for a check-up. I didn't grow taller until between the first and second year in high school. No one ever teased me and I don't think I had any kind of inferiority complex, I don't think I did, at least not very much, but.....(6 sec)... but I thought it was a bit, I don't know if it was something I thought of on my own, but I thought I was very short. (Interviewer: so you wish you were taller?) Yes. I actually do, maybe $3 \mathrm{~cm}$ taller, so I would be $1.80 \mathrm{~m}$. But I may grow some more, dad grew a lot when he was nearly twenty. I've done some work out in a fitness studio but .... I think it's ok to get into shape, but it's nothing I'm desperate about.

The fear of being objectified by this occupation with one's own body is significant. Some of the young men define - just like the male generations before them - any such interest as feminine, and remain indifferent when it comes to clothes and leave the shopping to their mothers. Others are interested in fashion, studying films and magazines for inspiration. Some of the young men who are preoccupied with style are 
explicitly 'anti-fashion,' which in some cases seems to become almost a mania to set oneself apart. This is a case where the more general mentality of individualisation seems to be turned into a drive for uniqueness - a drive that is much more prominent among the men than the women in this generation. The young men in our study seem to be involved in a precarious testing out of the borders of modern masculinity, where a weak and vulnerable body remains problematic. It is therefore remarkable that they actually admit to such vulnerability to a greater extent than the generations before them and even invest in body projects in new ways within some (masculine) limits.

Among the men of the middle generation we saw an increased focus on the female body. This is a much more ambivalent issue in the youngest generation. Some of them are clearly apologetic about the fact that a nice body on a girl means a lot since 'it shouldn't.' The middle-class boys think that sexual morals ought to be gender-neutral. Some of them actually prefer active girls, not least because that also reduces the risk of getting rejected. However, their descriptions of unwanted sexual situations also reveals that they are still ambivalent towards female initiatives. Some of the working-class boys mention girls who are sexually frivolous or unbearable when they get drunk. The emphasis on bodily and sexual difference is not seen among women to the same degree, so it may have a specific significance in securing a sense of masculinity. Since these same boys are clearly in favour of gender equality both at 18 and 30, this indicates that the issue of bodily and aesthetic difference in this generation of men is experienced as a separate aspect of gender, partly following its own logic, and not necessarily in conflict with degendering in other areas.

For both sons and daughters in this generation, there is much less emotional dis-identification with the same-sex parent as in the previous generation. The relationships to both parents are generally much more positive, however, in a form that also always emphasizes the importance of "being yourself". For some of the boys this leads to turning the generational hierarchy upside-down, as when one of them says about himself and his father: 'We are different people, but he is quite like me in many ways'. The feelings of identification or dis-identification with the parents are understood in terms of the parent's personality, rather than of his or her gender. The girls tend to see their mother as clever and rational (whereas the fathers are seen as more emotional persons) and take her as role models in combining work and family however, they also describe her as a separate person from themselves. Thus, the psychological autonomy vis-á-vis their mothers seems to have been strengthened in 
this generation of girls, but may give some ambivalence to their own female bodies where, in particular, the generative body is no straightforward matter. The problem is not lack of knowledge as in the previous generations: they all know what menstruation is and most of them depict the transition as rather undramatic. The young working-class women are even glad to feel grown-up and 'normal.' For the middle-class girls, however, the bodily transition is more disturbing. These middleclass girls are even more negative with regard to their menstruation than the women in the eldest generation. The period is characterised as 'a real bother,' 'hellish crap,' ' a little strange,' 'embarrassing' or directly 'icky' and does not match the otherwise liberated talk about bodily functions. A girl that we observed shouting across the classroom that she needed to borrow a tampon, tells us in the interview that she is completely disgusted by the blood (see also Rudberg, 1995).

Across all three generations of women, bodily appearances and looks represent an area that is much less surrounded by taboos than generative development and maturing processes. The differences between the two elder generations were a greater differentiation of flaws and assets, as well as drastically increased energy (and resources) invested in bodily improvements. Johanna's granddaughter Jenny, a middle class girl born in 1971, says:

I thought it was a bit weird to sit for times in front of the mirror. I didn't have any serious complexes, you know, things that really impeded me. But I wished that I had looked a bit different, that I was taller and had a better colour on my hair, this is dyed, you know, plus green eyes. In the last period I've been exercising a bit, but only because I get in such a bad mood if I'm not in form. I have slack muscles and must train my back.

In the youngest generation the detailed catalogue of flaws is replaced with a general preoccupation, bordering on obsession, with the body's size, shape and weight. It is an issue that is strongly present in the interviews regardless of whether the women feel overweight or not. The vast majority have been dieting, and quite a few have, as one of them puts it, had 'a touch of anorexia.' To almost stop eating makes one feel good, in control. Others make it a point that they have never been on a diet. The control over the body appear to be a more urgent issue to middle-class girls than working-class girls and they also seem to receive more ambiguous messages from their parents - ranging from feminist celebrations of their first period, to hints about watching their weight. Their relationship with their middle-class father is based on intellectual qualities rather than a positive evaluation of femininity. Perhaps it does 
not involve a direct devaluation of femininity, but tend to neutralise its embodied aspects? The girls enjoy dressing up for special occasions, but are sceptical about excesses like high heels and heavy make-up and they stick to more gender-neutral attire at school. A feminine appearance is a demanding act of balance for a middleclass girl: not too little, not too much, appropriate in time and place (see also Ambjörnsson, 2004 and Aapola et al., 2005 ). The more or less suspect femininity that a young middle-class girl has to avoid in order to become a modern, autonomous girl might also no longer be represented by her own mother the way it was in the middle generation, but rather be experienced as a more obscure, inner threat to her perceived identity. The body that is so central to modern self-construction has become a potential enemy, which they either manage to control or that lets them down by being beyond control. Thus, in spite of the young men taking a much more active interest in their appearances, there are only sparse signs that men and women in the youngest generation have become more similar to each other in the way they talk about and relate to their bodies.

When it comes to sexuality, there seems to be more degendering going on both in practice and in norms: at 18 , more of the women than the men have had heterosexual intercourse and more of the women than of the men report having had one-night stands. To have several partners is no longer regarded as a moral problem although both genders are aware of the fact that girls who 'sleep around' get a worse reputation than 'players,' which is an exclusively masculine term. The possibility of being the object of negative labelling does not seem to direct the young women's behaviour to any great extent. They initiate sexual relations more often than their mothers did, or at least they feel that they should be able to. In practice it is still rare, and is clearly felt to be risky business. The risks are evidently connected with fear of abuse, but even more with the fear of becoming an 'exposed girl'. To the young women in our sample an 'exposed girl' is not a girl who has several partners, but rather a girl who has sex to please others, not because she really wants to. They insist that when and how to have sex is seen as an individual choice. The ones who 'wait' till they are in a steady relationship do not argue in terms of morality (like their grandmothers) or risks of pregnancy (like their mothers), but in terms of what they felt as right for themselves. The young women still connect love and sex, but not as strongly as the middle generation. We can actually see some signs that love is becoming more problematic than sex for the youngest women as falling in love 
implies being more open and vulnerable than just having sex. This may indicate that the newly gained autonomy in young women has to be safeguarded and that especially heterosexual relations are still connected with the danger of dependency and asymmetry (see also Aapola et al., 2005).

There is much less desire involved in the descriptions of sexual encounters among the women, and their characterisations are actually not so different from the ones given by the women in the middle generation. Many of them depict their first time as a painful affair, involving blood and horror, while others laconically state that it was no great experience. When feelings enter the picture, women still tend to talk about sexual experiences in relational terms, as the ultimate intimacy, sometimes as a testimony to her erotic power over the boyfriend, in addition to being a way to feel grown-up. The sexual experience itself is not highlighted, and we recognise some of the instrumentality from the women of the previous generation, although not as explicit. The question is whether explicit sexual desire is still defined as a masculine affair even though both norms and practices are more degendered and individualised. Does this imply a gendered inertia when it comes to questions of body and sexuality that seem to go slower or even resist other degendering processes?

\section{The body project in a psychosocial and generational perspective}

I will emphasise two of the patterns that emerge when these generational portraits are seen in relation to each other. One is the intertwined character of the experiences of the body, the psychological work of becoming a separate person while preserving intimate bonds to others, and the gradual changes in gendered identities and subjectivities - and how this interacts with other aspects of sociocultural change in the different historical period. For the men in all generations, body and sexuality emerge as very important components in their feeling of masculinity. There is, however, also a change in the cultural and psychological meanings of this preoccupation. For the eldest generation, the strong male body is the working body and is thus a clear positive identification with their admired fathers. Other kinds of bodily preoccupations are felt as weak and feminine and not acceptable for a man. For the middle generation, their own bodies become more explicitly connected to male sexuality: masculinity is not secured by work, but by having a penis that is the right size compared to those of other men. This emphasis on the sexual meaning of masculinity may be seen in connection with their more insecure masculine selves in 
the self-other relations: you do not prove your masculinity by becoming a strong and admirable man like your father, but by possessing a male body. Thus, the loss of the possibility of becoming a man through the generational line seems here to amplify gender polarity. In the youngest generation penis size is also important, but other parts of the body may also add to the feeling of being a successful man. To be preoccupied with looks is no longer seen as an exclusively feminine business, but it does bring with it greater vulnerability and possible objectification. Hence, it is important to uphold gender difference to stagger the palpable risk of losing one's subject position and becoming the object through this preoccupation with one's own body.

Stressing sexual difference is not so important for the women, except for the middle generation where is works mainly as a route to liberation. The ways in which the young women deal with the generative and aesthetic body rather reveal something about how they relate to their mothers. In the oldest generation it is seen as a female curse, something mothers and daughters are equally subjected to, the silent and unwelcome sign of womanhood. In the middle generation the menstruating female body is also felt as a negative thing, but is taken more as a fact of life and even something that may contribute to some intimacy between girls. This may be surprising when seen in connection with the negative relationships to their mothers; however, it may also tell us about the basic care that these devalued mothers actually provided for their daughters, in addition to the decreasing taboo that came with more information about sexual reproduction. It is actually the youngest generation that reacts the most strongly against menstruation, which is also the case where they have feminist mothers who celebrate their menarche. In this generation, where the relationship between mothers and daughters is more about strengthening individuality rather than gender, the reproductive aspects of bodies seem to represent a hidden and uncontrollable femaleness that comes from nowhere. It also connects to the increased significance of the body as identity in this generation, where the main challenge is to stay in control of it. This gives the body an ambiguous meaning with regard to gender in this generation of women. The adornment of the body represents a more positive feminine identification for the young women in all generations, but this is never connected to identification with the mother-quite the opposite. For the eldest generation it is a pure joy to do with a luxury that serves as a contrast to the frugal work ethic of their mothers. For the middle generation the adornment becomes more desperate because it is often based on low self-esteem, and put in the service of 
heterosexual relations. For the youngest generation the pleasure of dressing up in feminine ways is back, but often also with a pressure for perfection that may destroy the joy and a fear of becoming too much gender. When it comes to sexuality it is beyond doubt that the young women have become subjects of sexual desire over these three generations. The double standards for girls and boys in relation to sexuality persist, but in a weaker form and with far fewer behavioural consequences. The danger for the girls in the youngest generation lies rather in the grip of the heterosexual matrix and they struggle with how to combine love and sexuality with being an autonomous subject. The fear of being a 'fallen subject' by letting oneself be pressured into sex seems now to be bigger than the prospect of being a 'fallen woman'. Whereas the young men may feel their gender identity threatened when they objectify their bodies, the young women may fear that the individuality they have fought for may once again be reduced to gender.

The second pattern I want to draw attention to is the increasing importance of the body project in the construction of self-identity over these three generations. The first signs of late-modern identities with emphasis on individuality, liberation and self-monitoring are seen in the messy stories of the middle generation, whereas in the youngest generation the reflexive self is more or less fully enfolded. The importance of being oneself, a unique person who makes one's own choices and is responsible for them instead of following old norms or standards of others, comes through clearly in the narratives and practices of the youngest generation. Also the focus on the body as a project to work on and being in control of is pronounced. It reveals itself as a new discourse about individuality and self-control as well as a new form of subjectivity with clear boundaries. The discourse does not, however, coincide completely with the subjectivity. This is seen in interviewees' feelings about not being able quite to meet their own standards of how free and enlightened they ought to be - the girls that 'should not' be too occupied with their looks or wait for the boys to take romantic and sexual initiatives, or the boys who 'should not' be so occupied with girls' bodies as they admit to be. Where the middle generation talks about dieting, exercise and being careful not to step over the lines sexually, the young generation talks about having 'a touch of anorexia', or about those who are 'hysterically occupied' with fitness, or are 'exposed girls'. Thus, it is not always clear whether their perceived problems around the body have increased or just found another language to be expressed in. From our interviews we also see that the activation of the discourse of anorexia immediately 
mobilises friends and adults around the girl and makes her a centre of the attention she feels she needs.

\section{The "fourth generation": the body project between increased sexualisation and escalating infantilisation?}

The youngest generation interviewed in our study are today approaching 50 and many of them themselves parents to teenage children. What has happened to this "fourth generation" and their relation to their bodies compared to their parents as 18-year olds in 1991? As our study indicates, the late-modern reflexive self was already installed in young people 30 years ago, but when we meet this reflexive self in young people today, it seems to be much more tormented. As mentioned in the introduction of this chapter, stress and press, low self-esteem and dissatisfaction with the body have increased dramatically among young people in the last decades. The polarisation has also grown so the negative tendencies do not apply to all, however they still give reason to ask what has happened to the mood of the reflexive self and her body?

I will consider two cultural trends that are new or at least have been amplified since we did our interviews in 1991. Since we have not actually interviewed "the fourth generation", my reflections on the further transformation of the bodily and psychosocial generational shifts will have to be speculative and purely suggestive. The first trend is the increased sexualisation of young women's bodies that took place during the 1990s (Harris, 2004; Aapola et al., 2005; Gill, 2007). If the young women in 1991 wanted to be thin and fit, young women today want to be even thinner and sexy. In the years after we did our first interviews there was a shift towards more sexualized fashions, symbolically verging on abuse and anorexia, and the use of ever younger and thinner models (Frisén et al., 2014). In 1991 the girls were wary that dressing too explicitly sexy could stage them as a 'traditional' or even an 'exposed girl', something that might have negated them as modern, autonomous girls. Especially for the middle-class girls, a sexy style was read as a class-marker, associated with working class girls. Since then the sexy body has become an ubiquitous female ideal with focus on large breasts, shaving of pubic hair, tight and revealing clothes, stilettos and an ultra feminine style of fashion, including printed messages on the clothes underlining the self-objectification (Tiggemann, 2012; Frisén et al., 2014; Holmquist Gattario et al., 2014). This trend has also affected the attire of career women, thus it underlines the necessity for a successful woman to be perfect 
not only in regard to professional competence, but also in feminine appearances. The focus on sexiness in women has revitalised the discourse of gender difference as important and natural, something which is seen, for instance, in new romantic trends connected to weddings and perfect homes and an increasingly gendered aesthetics and separation in children's clothing and toys. ${ }^{7}$ Needless to say, the effect of all this is multiplied by various types of mass media and Internet, bombarding especially young people with retouched photos of perfect and sexy bodies (Holmquist Gattario et al., 2014:2414). Young men are also targets for such gendered media messages, however, when it comes to body and appearance, the messages to girls are more consistent and by far outnumber the messages to boys (Smolak, 2004). The social media has also interfered with the processes of peer approval in adolescence by extending it to the unpredictable people's court of likes and dislikes.

As indicated, already the 18-year old girls we interviewed in 1991 struggled with the tensions between gender and individuality and their strategy was to tone down gender in order to prove themselves as successful autonomous subjects. In a situation where gender difference and sexiness have become part of what it means for a young woman to be successful, this has become a less obvious solution. It is not only a question of an increase in the areas in which one must strive for perfection, it also represents a special contradiction for young women, as the adorned, let alone explicitly sexualized, feminine body is symbolically connected to being an available object, not a subject. Thus, at the heart of modern identity construction - the body project itself - young women are caught in trap that the young men are not, namely the cultural contradiction between being a subject and being a woman (Beauvoir, 1949; Bordo, 1993; Davis, 1995). The young women of today have to navigate between gender discourses that disclaim the significance of gender (girls can do anything!), and discourses of individuality that come with gendered subtitles (girls can be subjects... but they cannot escape being objects too). The young women find themselves in a catch 22 where they have been told that autonomous modern girls do not have to make themselves objects for men's gaze, but at the same time experience exactly this in order to become and also feel to be successful young women. Instead of just focussing on the adaption and pain this implies, one could ask what kind of agencies it may open up for. For instance, could it be that the \#MeToo explosion draws its energy exactly from this deepened split in the self-image of young women? And could it be exactly their development also as capable subjects that makes them 
able to take issue with the increasing sexualisation of their bodies (at least when they are at work)? The reverberation of \#MeToo among young women, may indicate that the strong girls are on the path to take issue with themselves as exposed girls.

The other trend I want to mention and which may be even harder to be optimistic about right now, is the increasing pressure on young people to be perfect as well as the self-blame if one becomes 'a loser'. The pressure on appearances has increased and become more and more unattainable - 'the normal has become a fantasy' as Frost says (1995: 80) - and the association between fat and unfit and bad character and morals has become more pervasive since the 1990s (Bordo, 2003, Frisén et al., 2014). But also the pressure to get good grades, good education, successful careers and families has radically increased since the new millennium. We know that especially girls experience pressure in school to get good enough grades (Sletten and Bakken, 2016; Bakken 2018; Madsen 2018). ${ }^{8}$ This pressure to succeed in an increasingly harder competitive environment has also introduced new forms of adult monitoring and control of young people, a new form of all-embracing 'educationalisation' and 'pedagogiciation' of young people's lives (Hegna et al. 2017; Sefton-Green and Erstad; 2019) which stands in a particularily peculiar contrast to the increased sexualisation of ever younger girls. We see this new monitoring in the increasing test- and assessment-regimes in schools and the dominance of adultorganised leisure activities. Also parents appear to structure the lives of their children much more than earlier. This is especially the case in the middle-class where there is a strong inclination to optimalise the offspring's life-chances through routines for homework and a healthy life, and attending organised sports and music lessons (Vincent and Ball, 2007; Stefansen and Aarseth, 2011; Aarseth, 2015). This may further feed the idea among young people that their bodies should also be an object of forming, constructing and styling (Hegna et.al., 2017). Thus, we may see the contours of a new situation where young people experience increasing monitoring and control and at the same time feel increasingly responsible for their own success. This may contribute not only to confusion, but also to increased shame on the individual level. The mismatch between being sexualised by media and fashion and being infantilized by adult monitoring may add further confusion and shame. One may also speculate to what degree the increased parental monitoring may alter the conditions for the development of autonomy in children and young people. Even though the relationship between Norwegian adolescents and their parents is more positive than 
ever (the trend from the three generations has continued (Bakken, 2018)), there are also signs that may indicate that young people are becoming more dependent on their parents psychologically and financially. Will this risk to impeding the development of psychological boundaries and autonomy in this young generation - in a situation where boundaries and autonomy are more important than ever? In that case their psychological situation may, surprising enough, share some traits with their grandparents - the middle generation in our study - rather than with their parents. The young people of the 1960s and 1970s were also confronted with a new societal context without having been psychologically prepared for it. The result of that contradiction was the youth revolt and later the Women's Movement. What might come from the squeezed generation of today? Could \#MeToo be just a start?

Finally, one could also ask to what degree youth research itself adds fuel to the fire by the continuous and close monitoring of young people's wellbeing and the attention these studies get in the media (Nordtug and Engelsrud, 2016; Madsen, 2018). As the Norwegian psychologist Ole Jacob Madsen asks, the alarming numbers of young people with psychological stress may become a self-fulfilling prophecy by offering young people a diagnostic vocabulary through which to understand themselves. The youth researchers accuse the 'assessment hysteria' in the educational system for the increasing pressure on young people, however, such an assessment hysteria could also be said to characterise the youth researchers themselves who, on behalf of the state, repeatedly ask young people how they 'really feel'. When the results of this research gets the attention of the media and young people say that they "recognize themselves" in the diagnostic categories, the circular movement is complete (Madsen, 2018: 156). But as has been documented, self-reported stress in surveys finds a much higher prevalence of psychological symptoms than clinical interviews of the same samples do (Rosenvinge et al., 1999; Nordtug and Engelsrud 2016). Thus, the diagnostic language looses meaning by becoming a new selfobjectivising vocabulary with little connection to the lived life and subjectivity of the young people (Løkke, 2014).

This methodological warning does not imply that young people today do not experience increased bodily concerns and psychological pressure - there are good reasons to believe that they do and to dismiss this would be to ignore the actual effects that the neo-liberal arrangements and culture have on the lives of young people. However, the patologising discourses contribute to individualise and alienate 
the experience of strain, highlighting only the abstract victimhood, not the lived subjectivity and situated agency of young people. The generational analysis offered in this chapter indicates that the outcome of young people's pains and struggles needs a longer time perspective to be known.

Notes

${ }^{1}$ A recent survey from Norway (Eriksen et al, 2017; Bakken, 2018)found that $35 \%$ of girls against $10 \%$ of boys felt a social pressure to display a good-looking body and that $20 \%$ of the girls against $41 \%$ of the boys reported that they were satisfied with their looks.

${ }^{2}$ A representative survey among Norwegian adolescents in 1996, 2006 and 2015 indicate almost a doubling in depressive symptoms among girls in this 20 year period, especially the last 10 years, but only little change among boys. In $201526 \%$ of the girls and $9 \%$ of the boys (age 14 to 17) reported a high level of depressive symptoms, however the variation has also increased, indicating that it is still a minority that suffer from body dissatisfaction and self-esteem problems (Sletten and Bakken 2016). There has also been a marked increase in the use of painkillers among adolescent girls in recent years (Madsen, 2018).

${ }^{3}$ Girls surpassed boys in frequency of high school graduation in 1975, and during the 1980s they also became the majority in higher education (Statistics Norway http://www.ssb.no/a/english/histstat). The last 20 years the gender distribution in higher education has been stable with approximately 60 percent women and 40 percent men. The choice of field is very unbalanced in terms of gender with a majority of women in humanities, social sciences and health sciences and a majority of men in technology, engineering and natural sciences. However, women have within the last decades become a majority also in some areas that earlier were dominated by men like medicine, psychology, law and economy. These fields have high admission levels in terms of grades and as girls on average finish high school with better grades than boys, they have better chances in getting into these popular fields.

${ }^{4}$ The study was conducted at the University of Oslo by Monica Rudberg and me and has been presented in Norwegian in Nielsen \& Rudberg (2006) and in English in Nielsen (2017) - in addition to several articles of which some are included in the list of references.

${ }^{5}$ Since it turned out that not everyone in the two older generations wanted to take part in the study (a disproportionate number of the fathers declined and more of the grandfathers than of the grandmothers had passed away), we ended up with a sample of 22 female and 12 male chains consisting of either two or three generations. Total number of interviewees: 88; total number of interviews: 121.

${ }^{6}$ For more information and reflection on methodological issues, see Nielsen (2003) and Nielsen (2017). The following analysis of the three generations is an abbreviated and partly rewritten account of some of the empirical analyses in Nielsen (2017). As 
Monica Rudberg was co-author on the empirical chapters and especially on the parts about body and sexuality, she should also be credited for the analyses as they appear in this chapter.

${ }^{7}$ It is interesting to see how such a cultural trend may have different effects for different age groups. In the interviews with our youngest generation in 2011 when they approached 40, most of them still adhered to a feminist agenda and were eager supporters of modern gender equality politics, for instance father quotas and women in leadership and politics. However, on the symbolic level they now combined this with an aesthetic and emotional joy of gender differences. The issue of the new market-driven gender separation of childhood - pink for girls, blue for boys - is not something they found important to engage in. 'They've expired, those issues,' one of them say, with reference to the feminism of their mothers (Nielsen, 2017). However, indulging in gender as aesthetics and life style will mean something quite different for middle-aged people who feel secure about their own identities and capacities, as compared to adolescents.

${ }^{8}$ Around $40 \%$ of the young people in the Norwegian study mentioned in the introduction agreed with the statements "I feel that everything is an effort" and "I worry too much about things" and the majority of these were girls (Sletten 2016, Bakken 2018).

\section{References}

Aapola S, Gonick M, and Harris A (2005) Young Femininity: Girlhood, Power and Social Change. Basingstokes: Palgrave Macmillan.

Aarseth H (2015) A sound foundation? Financial elite families and egalitarian schooling in Norway. In Maxwell C, Aggleton P (eds) Elite Education: International Perspectives. London: Routledge.

Bakken A (2018) Ungdata 2028. Nasjonale resultater [Youth data 2018. National results]. Oslo: NOVA.

Beauvoir, S de (1949/1979) The Second Sex. Middlesex: Penguin.

Bengs C (2000) Looking Good. A study of gendered body ideals among young people. Umeå: Umeå University.

Bordo S (1993) Unbearable Weight: Feminism, Western culture, and the body. Berkeley and Los Angeles: University of California Press.

Brumberg, J J (1997) The Body Project: An Intimate History of American Girls. New York.

Currie C et al. (eds) (2012) Social determinants of health and well-being among young people. International report from the 2009/2010 survey. In Health Behaviour in School-Aged Children (BHSC) Study. Copenhagen: WHO Regional Office for Europe. .

Davis K (1995) Reshaping the Female Body: The Dilemma of Cosmetic Surgery. New York: Routledge.

Driscoll C (2002) Girls: Feminine Adolescence in Popular Culture and Cultural Theory. New York: Columbia University Press.

Eriksen I M, Sletten M A, Bakken A, and von Soest T (2017) Stress og press blant unge [Stress and press amoung young people]. Oslo: NOVA. 
Frisén A, Holmqvist Gattario K, and Lune C (2014) Projekt perfekt. Om utseendekultur och kroppsuppfattning [Project perfect. Cultures of apperances and body image]. Stockholm: Natur \& Kultur.

Frost L (2001) Young Women and the Body: A Feminist Sociology. Basingstoke: Palgrave Macmillan.

Frost L (2005) Theorizing the Young Women in the Body. Body \& Society 11(1):6384.

Giddens A (1991) Modernity and Self-Identity. Cambridge: Polity Press.

Gill R (2007) Gender and the Media. Cambridge: Polity Press.

Harris A (2004) Future Girl: Young Women in the Twenty-First Century. New York and London: Routledge.

Hegna K, Eriksen I M, Sletten M A, Strandbu Å, and Ødegård G (2017) Ungdom og psykisk helse - endringer og kontekstuelle forklaringer [Youth and mental health - changes and contextual explanations]. In Bunting M, Moshuus G H (eds) Skolesamfunnet. Kompetansekrav og ungdomsfellesskap. Oslo: Cappelen Damm Akademisk.

Holland J, Ramazanoglu C, Sharpe S, and Thomson R (1998) The Male in the Head: young people, heterosexuality and power. London: the Tuffnell Press.

Holmqvist Gattario K, Frisén A, and Anderson-Fye, E (2014) Body Image and Child Well-Being. In Ben-Arieh A et al. (eds) Handbook of Child Well-Being. Dordrecht: Springer Science+Business Media.

Holmqvist K, Frisén A (2010) Body Dissatisfaction Across Cultures: Findings and Research Problems. European Eating Disorders Review 18(2):133-46.

Kehily M J (2008) Taking Centre Stage? Girlhood and the Contradictions of Femininity across Three Generations. Girlhood Studies 1(2):51-71.

Kvalem I L (2007) Ungdom og kroppsbilde [Youth and body image].In Kvalem I L, Wichstrøm, L (eds) Ung i Norge. Oslo: Capplen.

Kvalem I L, Strandbu Å (2013) Body Talk - Group Specific Talk? A Focus Groups Study of Variation in Body Ideals and Body Talk among Norwegian Youth. Young - Nordic Journal of Youth Resarch 21(4):327-46.

Lees S (1993) Sugar and Spice: Sexuality and the Adolescent Girl. London: Penguin.

Løkke P A (2014) Jenters stumme raseri - i diagnosenes tidsalder [The muted rage of girls - in the era of diagnoses]. Tidsskrift for Norsk Psykologforening 51:76772.

Madsen O J (2018) Generasjon prestasjon [Generation performance]. Oslo: Universitetsforlaget.

McRobbie A (2009). The Aftermath of Feminism: Gender, Culture and Social Change. London: Sage.

Nielsen H B (2003) Historical, Cultural, and Emotional Meanings: Interviews with Young Girls in Three Generations. NORA - Nordic Journal of Women's Studies 11(1):14-26.

Nielsen H B (2017). Feeling Gender. A generational and psychosocial approach. London: Palgrave Macmillan.

Nielsen H B, Rudberg M (2006). Moderne jenter: Tre generasjoner på vei [Modern girls: Three generations on their way]. Oslo: Universitetsforlaget.

Nordtug B, Engelsrud G (2016) Boken som mangler, ord som går på tomgang og sykt flinke jenter: Kunnskap og helse [The missing book, words without meaning and insanely clever girls: Knowledge and health]." Tidsskrift for kjønnsforskning 40(3-4):151-68. 
Oinas E (2001) Making Sense of the Teenage Body. Sociological Perspectives on Girls, Changing Bodies and Knowledge. Åbo, Finland: Åbo Akademi University Press.

Ricciardelli L A, Yager Z (2016). Adolescence and Body Image. Oxon, UK, and NY: Routledge.

Rosenvinge, J H, Sundgot-Borgen J, and Børresen R (1999). The Prevalence and Psychological Correlates of Anorexia Nervosa, Bulimia Nervosa and Binge Eating Among 15-Year-Old Students: A Controlled Epidemiological Study. European Eating Disorders Review 7:382-91.

Rudberg M (1995) A bloody story? On construction of bodily gender among young girls. NORA - Nordic Journal of Feminist and Gender Research 3(1):32-44.

Sefton-Green J, Erstad O (eds) (2019) Learning Beyond the School: International Perspectives on the Schooled Society. London and New York: Routledge.

Skeggs B (1997) Formations of Class and Gender. London: Sage.

Sletten M A, Bakken A (2016) Psykiske helseplager blant ungdom - tidstrender og samfunnsmessige forklaringer [Psychic health issues of young people - time trends and social causes]. Oslo: NOVA.

Smolak L (2004) Body image in children and adolescents: where do we go from here? Body Image 1(1):15-28.

Søland B (2000) Becoming Modern: Young Women and the Reconstruction of Womanhood in the 1920s. Princeton and Oxford: Princeton University Press.

Stefansen K, Aarseth H (2011) Enriching intimacy: the role of the emotional in the 'resourcing' of middle - class children. British Journal of Sociology of Education 32(389-405).

Tiggemann M (2012) Sociocultural perspectives on the body. In Cash T F (ed) Encyclopedia of body image and human appearance, vol.2. London: Elsvier.

Vincent C, Ball S J (2007) Making up' the middle-class child: Families, activities and class dispositions. Sociology 41(6):1061-77.

Wertheim E H, Paxton S J (2012) Body image development: Adolescent girls. In Cash T F (ed) Encyclopedia of body image and human appearance. London: Elsvier.

Wichstrøm L (1999) The emergence of gender differences in depressed mood during adolescence: The role of intensified gender socialization. Developmental Psychology 35:232-45. 